УДК 543.544:547.913

\title{
ИЗУЧЕНИЕ ЗАВИСИМОСТИ АНТИОКСИДАНТНОЙ АКТИВНОСТИ ЭФИРНЫХ МАСЕЛ ПОЧЕК ГВОЗДИКИ, ЛИМОННОЙ ТРАВЫ, КАРДАМОНА И ЯГОД МОЖЖЕВЕЛЬНИКА ОТ КОНЦЕНТРАЦИИ МАСЛА МЕТОДОМ КАПИЛЛЯРНОЙ ГАЗОВОЙ ХРОМАТОГРАФИИ
}

\section{(C) А.Л. Самусенко}

\author{
Институт биохимической физики им. Н.М. Эмануэля РАН, ул. Косыгина, 4, \\ Москва, 119991 (Россия), e-mail: Samusenko.alexey@rambler.ru
}

Методом капиллярной газо-жидкостной хроматографии исследована зависимость величины антиоксидантной активности от концентрации эфирных масел почек гвоздики (Caryophyllus aromaticus L.), лимонной травы (Cymbopogon citratus), кардамона (Elettaria cardamoтum) и ягод можжевельника (Juniperus pinchoti).

Оценка антиоксидантных свойств проведена по реакции окисления транс-2-гексеналя в соответствующую карбоновую кислоту. Найдено, что зависимость величины антиоксидантной активности масел от их концентрации непосредственно связана со скоростью изменения содержания основных веществ-антиоксидантов в составе изученных эфирных масел при длительном хранении на свету. Отмечено, что присутствие в составе масел сильных антиоксидантов даже в относительно низких количествах может заметно влиять на величину их антиоксидантной активности и на ее зависимость от концентрации масла. Обнаружена резко выраженная зависимость антиоксидантной активности от концентрации масла для гвоздичного и лемонграссового масел. Низкие концентрации всех изученных масел, кроме масла гвоздики, не оказывали ингибирующего действия на окисление тест-альдегида.

Ключевые слова: пряно-ароматические растения, эфирные масла, антиоксидантная активность, капиллярная газовая хроматография.

\section{Введение}

В последнее время в результате многочисленных исследований установлена биологическая активность эфирных масел пряноароматических растений, в том числе антиоксидантная [1-3]. Поскольку пряноароматические растения являются источниками природных антиоксидантов, использование их эфирных масел представляет альтернативу синтетическим антиоксидантам, так как последние потенциально опасны для здоровья человека [4]. Поэтому изучение антиоксидантной активности (АОА) эфирных масел пряноароматических растений является важной задачей для пищевой, фармакологической и парфюмерной промышленности, косметической химии и ароматерапии.

Биологическая активность эфирных масел зависит от присутствующих в них основных компонентов, т.е. от их состава. Известно, что наличие в составе масел циклических монотерпеновых углеводородов с двумя двойными связями в цикле $\alpha$ - и $\gamma$-терпиненов, $\alpha$-терпинолена и сабинена, а также эвгенола, тимола и карвакрола [5-6] обусловливает их антиоксидантные свойства. Относительно недавно предложены компьютерные программы, позволяющие предсказать АОА 32 эфирных масел, используя данные о составе их активных компонентов [7].

Ранее на примере окисления альдегидов мы провели сравнительную оценку АОА 12 эфирных масел, содержащих в своем составе монотерпены ( $\gamma$-терпинен и $\alpha$-терпинолен), сесквитерпены (зингиберен и $\beta$-кариофиллен), фенольные соединения (эвгенол) и цитраль, которые обладают высокой АОА [8-9]. Однако концентрация масел в растворе была относительно высока, и исследования при других значениях

Самусенко Алексей Леонидович - научный сотрудник, тел.: (499) 135-78-94, e-mail: Samusenko.alexey@rambler.ru концентрации масла не проводили. В литературе также недостаточно данных по изучению концентрационной зависимости АОА эфирных масел. В связи с 
этим было интересно изучить влияние концентрации обладающих АОА эфирных масел на скорость окисления альдегида и сопоставить полученные результаты с количественным изменением состава активных компонентов масел.

Цель работы - изучить зависимость АОА эфирных масел почек гвоздики, лимонной травы, кардамона и ягод можжевельника от их концентрации в растворе и соотнести полученные данные с изменением содержания основных веществ-антиоксидантов, входящих в состав масел.

\section{Экспериментальная часть}

Исследовали свежие образцы эфирных масел почек гвоздики (Caryophyllus aromaticus L.), кардамона (Elettaria cardamomum), ягод можжевельника (Juniperus pinchoti) - все три образца фирмы «Plant Lipids Ltd» (Индия), а также масла лимонной травы (лемонграссовое масло) (Cymbopogon citratus) - фирмы «Synthite» (Индия).

Для оценки АО свойств эфирных масел в 50 мл $t$-гексана растворили 400 мкл транс-2-гексеналя и 400 мкл $н$-додекана (8 мкл/мл); последний служил внутренним стандартом. Раствор разделили на аликвоты по 2 мл, которые поместили в стеклянные пробирки объемом 10 мл, и добавили по 200, 100, 50 или 20 мкл эфирных масел почек гвоздики, лимонной травы, кардамона и ягод можжевельника (всего 16 образцов). Концентрации масла в приготовленных растворах составляли 9,09; 4,76; 2,44 и 0,99\%, но для удобства сравнения и построения диаграмм были условно приняты равными 10; $5 ; 2,5$ и 1\% соответственно. В контрольный образец масло не добавляли. Каждый образец был приготовлен двукратно. Образцы в закрытых пробками пробирках держали на свету при комнатной температуре в течение 145 сут. Источником света служило естественное освещение в лаборатории. Каждую неделю пробирки открывали и продували 10 мл воздуха с помощью пипетки. Количественное содержание гексеналя в пробирках определяли методом капиллярной газовой хроматографии через каждые 8-12 сут. в первые 3 мес. хранения, а затем с интервалом в 1 мес. Изменения в составе эфирных масел фиксировали через 1, 2, 3, 4 и 5 мес. с начала хранения.

Газохроматографический анализ образцов эфирных масел проводили на хроматографе «Micromat412» фирмы «Nordion Instr.» (Финляндия) на кварцевой капиллярной колонке SPB-1 («Supelco», CША, 35 м $\times 0,32$ мм, толщина слоя фазы 0,25 мкм) при программировании температуры колонки от 60 до $250{ }^{\circ} \mathrm{C}$ со скоростью $8 \%$ мин. Скорость газа-носителя гелия составляла 1 мл/мин, температура инжектора и пламенноионизационного детектора $-250^{\circ} \mathrm{C}$. Идентификацию компонентов в образцах масел осуществляли на основе величин индексов удерживания путем их сопоставления с литературными [10] или экспериментальными данными, полученными нами. Количественное содержание гексеналя и компонентов эфирных масел рассчитывали по отношению площадей пиков, соответствующих веществам и внутреннему стандарту, содержание которого принимали кратным 8 мкл/мл. Степень окисления гексеналя и компонентов эфирных масел (отн. \%) определяли по отношению к их содержанию в исходных образцах.

\section{Результаты и обсуждение}

Для оценки АОА исследуемых эфирных масел мы использовали тест «альдегид/карбоновая кислота» [11]. Этот метод успешно применяли для проверки АО активности летучих экстрактов из различных растений, например гвоздики, эвкалипта [12] и некоторых сортов зеленого и черного чая [13]. Тествещество и критерий для оценки АОА изучаемых масел выбраны аналогично работе [14].

На рисунке 1 представлена зависимость АОА масел от их концентрации в растворе. Как видно из рисунка 1 , все исследованные масла обладали различной АОА. В контрольном растворе (К) период полуокисления (ПО) альдегида составлял 21 сут., в то время как наличие в растворе эфирных масел в той или иной степени ингибировало окисление альдегида, причем степень ингибирования зависела от их концентрации в системе.

При уменьшении концентрации масла с 10 до 5, 2,5 и 1 об. \% мы отмечали последовательное снижение АОА системы «альдегид - эфирное масло». Наименее резкое и приблизительно одинаковое снижение АОА при уменьшении концентрации масла в системе наблюдали для масел ягод можжевельника и кардамона (рис. 1); в маслах же почек гвоздики и лимонной травы эта зависимость выражена значительно резче. Однако в данном случае нельзя сделать однозначный вывод о том, в каком именно масле наблюдали наиболее резкое снижение АОА при уменьшении концентрации масла в системе - в масле почек гвоздики или в 
лемонграссовом масле. Мы не смогли определить ПО альдегида для 10\%-ного масла гвоздики вследствие того, что за период исследования (145 сут.) окисление альдегида произошло только на 22, а не на 50\%. Основным компонентом масла гвоздики является сильный антиоксидант фенольного типа - эвгенол.

Содержание эвгенола в составе гвоздичного масла составляет более $80 \%$, что при высокой концентрации масла в системе «альдегид - масло - гексан» приводит, естественно, к сильному ингибированию окисления альдегида. Поэтому на рисунке 1 представлены данные только для 1-5\%-ных концентраций масла гвоздики. Изменение содержания эвгенола в растворе в процессе автоокисления масла гвоздики представлено на рисунке 2, $а$, где показано, что в 10\%-ном масле гвоздики содер-<smiles>C=CCc1ccc(O)c(OC)c1</smilesжание эвгенола в растворе в пределах ошибки хроматографического определения не изменяется за 110 сут. процесса автоокисления.

Рис. 1. Зависимость величины ПО транс-2гексеналя от концентрации эфирного масла в растворе. Концентрации масел: $1-10 ; 2-5$; $3-2,5 ; 4-1 \%$ об.

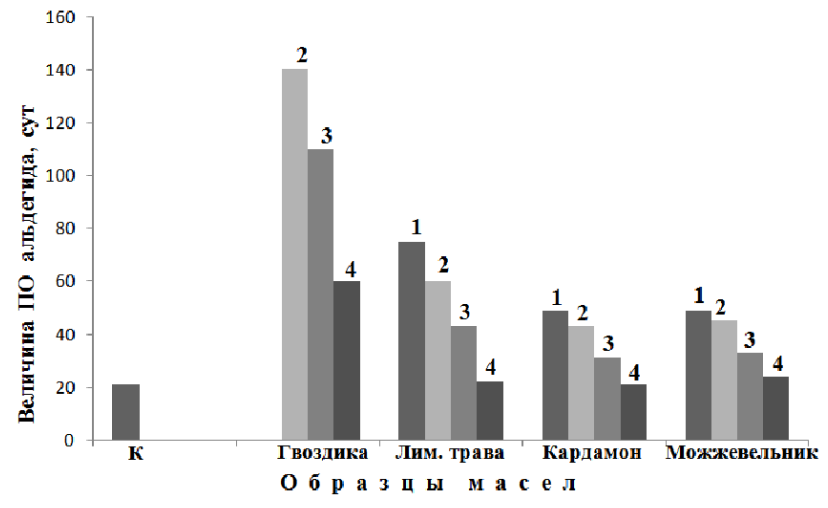

В отличие от масла гвоздики, в лемонграссовом масле, где содержание основного антиоксиданта цитраля - составляло в изученном образце около 83\%, автоокисление происходило значительно быстрее. Как известно, цитраль является смесью изомеров - транс- (гераниаль) и циис-(нераль):<smiles>CC(C)=CCCC(C)=CC=O</smiles>

гераниаль (транс-)<smiles>CC(C)=CCCC(C)=CC=O</smiles>

нераль (цис-)

Транс-изомер окислялся быстрее, чем цис-изомер, и к концу периода ПО альдегида (75 сут.) в 10\%ном лемонграссовом масле оставалось неокисленным только 15\% гераниаля и 20\% нераля от их исходных количеств; при этом изменялся запах масла. Аналогичный характер окисления цитраля в присутствии различных одорантов отмечен также в работе [15]. Кроме того, в состав лемонграссового масла входит небольшое (около 2,5\%) количество гераниола, который в изученном образце масла полностью окислялся до гераниаля:
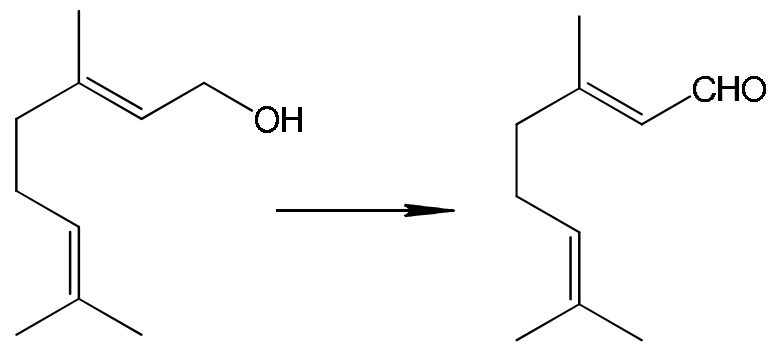
Очевидно, что уменьшение количества гераниаля в лемонграссовом масле происходило бы еще быстрее, если бы не этот конкурирующий процесс. На рисунке 2, б приведено изменение содержания гераниаля в растворе в процессе автоокисления лемонграссового масла. Поскольку содержание эвгенола в гвоздичном масле и цитраля в лемонграссовом приблизительно одинаково, из полученных нами данных очевидно, что антиоксидант фенольного типа эвгенол проявлял большую устойчивость к окислению на свету, чем альдегид цитраль.

Эфирные масла кардамона и ягод можжевельника имели одинаковую и сравнительно низкую антиоксидантную активность: ПО альдегида составлял всего 49 сут. в 10\%-ных растворах этих масел. Наблюдали менее резко выраженную зависимость АОА от концентрации масла в растворе по сравнению с маслами гвоздики и лимонной травы. Как видно из рисунка 1, наименее резкую концентрационную зависимость АОА наблюдали для масла можжевельника. Основными компонентами в масле кардамона являлись 1,8-ци-

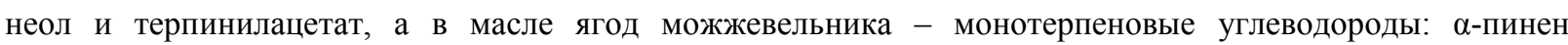
и $\beta$-мирцен. Мониторинг состава указанных масел показал, что содержание всех этих соединений изменялось за время изучения незначительно, и, следовательно, они не могли быть ответственными за изменение AOA в процессе автоокисления масел кардамона и можжевельника. Однако в состав обоих масел входили и сильные антиоксиданты - $\alpha$ - и $\gamma$-терпинены, $\alpha$-терпинолен, а также $\beta$-кариофиллен, правда, в относительно небольших количествах (их суммарное исходное содержание составляло 1,40 и 2,02\% для кардамона и можжевельника соответственно). За время, равное ПО альдегида, $\alpha$ - и $\gamma$-терпинены, $\alpha$-терпинолен полностью окислялись, частично неокисленным оставался лишь $\beta$-кариофиллен. Изменение суммарного содержания указанных выше антиоксидантов (отн. \%) в процессе автоокисления масел кардамона и ягод можжевельника представлено на рисунках 2, в и г.

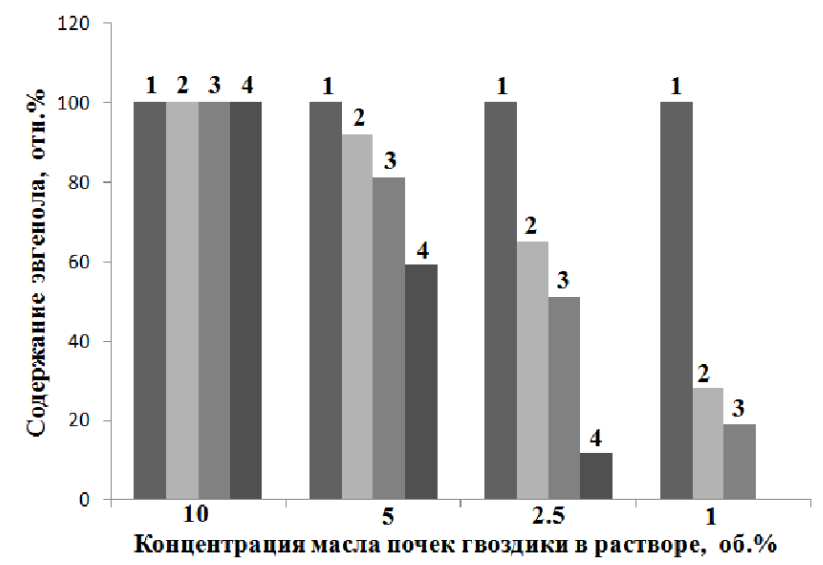

а) гвоздика - эвгенол

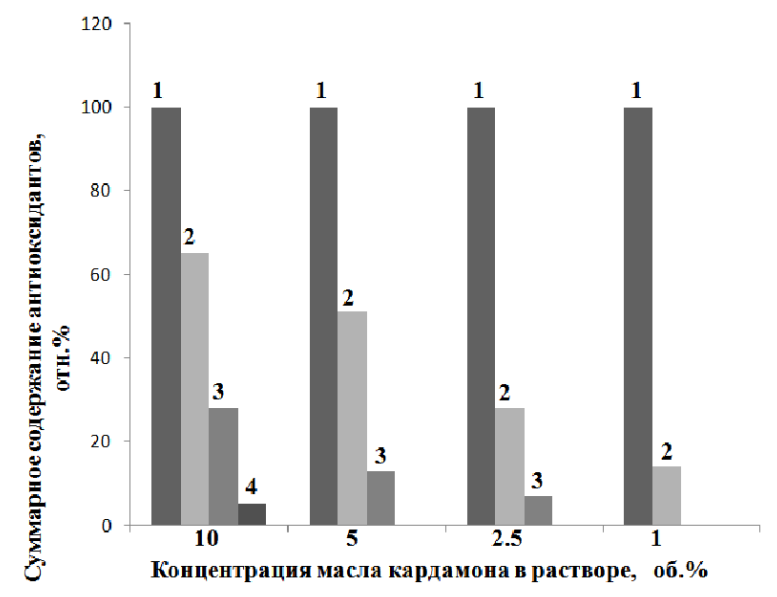

в) кардамон - суммарное содержание $\alpha$ - и $\gamma$ терпиненов, $\alpha$-терпинолена, $\beta$ - кариофиллена

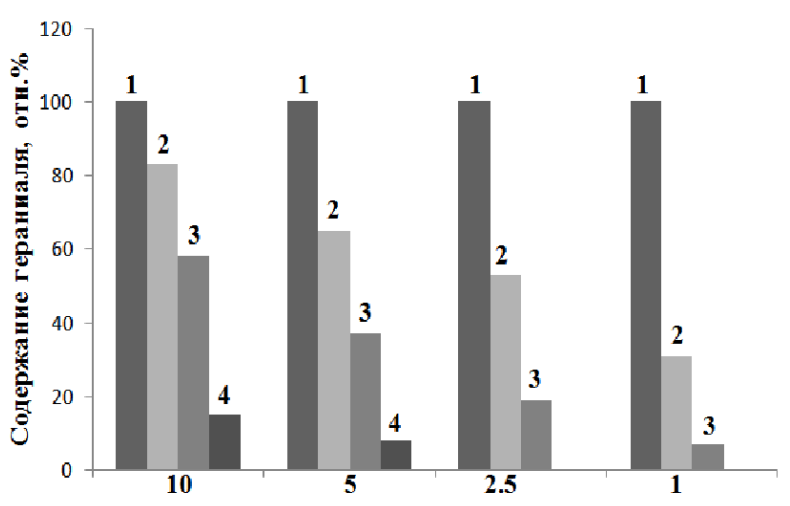

Концентрация масла лимонной травы в растворе, об.\%

б) лимонная трава - гераниаль

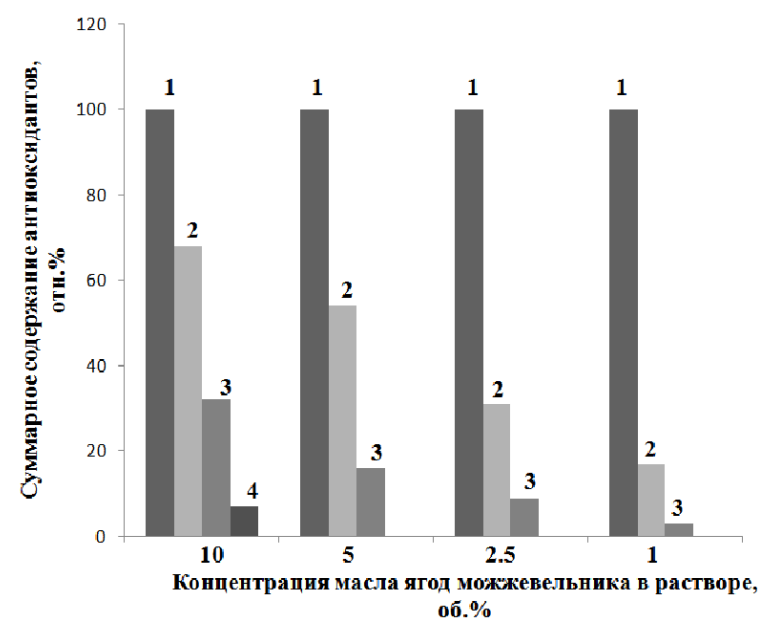

г) можжевельник - суммарное содержание $\alpha$ - и $\gamma$ терпиненов, $\alpha$-терпинолена, $\beta$-кариофиллена

Рис. 2. Изменение содержания основных веществ - антиоксидантов в эфирных маслах при различных концентрациях масла в растворе: $1-0 ; 2-30 ; 3-60 ; 4-110$ сут. процесса автоокисления 
Полученные результаты свидетельствуют о том, что присутствие в составе масел сильных антиоксидантов даже в относительно низких количествах может заметно влиять на величину их АОА и на ее зависимость от концентрации масла в растворе. Знания о концентрационной зависимости АОА масел позволяют составлять композиции на основе одного либо нескольких эфирных масел с заранее заданными свойствами.

\section{Выводы}

Методом капиллярной газовой хроматографии обнаружено, что зависимость величины антиоксидантной активности эфирных масел почек гвоздики, лимонной травы, кардамона и ягод можжевельника от их концентрации в системе «альдегид - масло - гексан» непосредственно связана со скоростью изменения содержания основных веществ-антиоксидантов в составе изученных масел при длительном хранении на свету.

Наиболее резкую зависимость антиоксидантной активности от концентрации наблюдали для масла гвоздики и лимонной травы, а наименее - для масла ягод можжевельника. Отмечено, что даже при низких концентрациях (1 об. \% в растворе) масло гвоздики, содержащее в составе сильный антиоксидант фенольного типа эвгенол обладает достаточно высокой АОА по отношению к окислению альдегида.

Присутствие в составе масел сильных антиоксидантов, таких как $\alpha$ - и $\gamma$-терпинены, $\alpha$-терпинолен и $\beta$-кариофиллен, даже в относительно низких количествах может заметно влиять на величину АOA и на ее зависимость от концентрации масла в растворе.

\section{Список литературы}

1. Burt S. Essential oils: their antibacterial properties and potential applications in foods // Int. J. Food Microbiol. 2004. Vol. 94, N3. Pp. 223-253.

2. Hsu F.-L., Li W.-H., Yu C.-W., Hsieh Y.-C., Yang Y.-F., Liu J.-T., Shih J., Chu Y.-J., Yen P.-L., Chang S.-T., Liao V. H.-C. In Vivo Antioxidant Activities of Essential Oils and Their Constituents from Leaves of the Taiwanese Cinnamomum osmophloeum // J. Agric. Food Chem. 2012. Vol. 60, N12. Pp. 3092-3097.

3. El-Ghorab H., Nauman M., Anjum F.M., Hussain S. and Nadeem M. A Comparative Study on Chemical Composition and Antioxidant Activity of Ginger (Zingiber officinale) and Cumin (Cuminum cyminum) // J. Agric. Food Chem. 2010. Vol. 58, N14. Pp. 8231-8237.

4. Kulawik P., Özogul F., Glew R., Özogul Y. Significance of Antioxidants for Seafood Safety and Human Health // J. Agric. Food Chem. 2013. Vol. 61, N3. Pp. 475-491.

5. Chizzola R., Michitsch H., Franz C. Antioxidative properties of Thymus vulgaris leaves : comparison of different extracts and essential oil chemotypes // J. Agric. Food Chem. 2008. Vol. 56, N16. Pp. 6897-6904.

6. Ruberto G., Baratta M. Antioxidant activity of selected essential oil components in two lipid model systems // Food Chem. 2000. Vol. 69, N2. Pp. 167-174.

7. Cabrera A.C., Prieto J.M. Application of artificial neural network to the prediction of the antioxidant activity of essential oils in two experimental in vitro models // Food Chem. 2010. Vol. 118, N1. Pp. 141-146.

8. Samusenko A.L. Comparative evaluation of antioxidant properties of spice-aromatic plant essential oils // Oxidation Communications. 2008. Vol. 31, N2. Pp. 275-284.

9. Samusenko A.L. Investigation of antioxidant activity of essential oils from lemon, pink grapefruit, coriander, clove and its mixtures by capillary gas chromatography // Oxidation Communications. 2008. Vol. 31, N3. Pp. 519-526.

10. Jennings W., Shibamoto T. Qualitative Analysis of Flavor and Fragrance Volatiles by Glass Capillary Gas Chromatography. New York ; London ; Sydney ; Toronto ; San Francisco, 1980. 472 p.

11. Lee K.G., Shibamoto T. Determination of antioxidant potential of volatile extracts isolated from various herbs and species // J. Agric. Food Chem. 2002. Vol. 50, N17. Pp. 4947-4952.

12. Lee K.G., Shibamoto T. Inhibition of malonaldehyde formation from blood plasma oxidadation by aroma extracts and aroma components isolated from clove and eucalyptus // Food and Chem. Toxicol. 2001. Vol. 39, N12. Pp. 1199-1204.

13. Yanagimoto K., Ochi H., Lee K.G., Shibamoto T. Antioxidative activities of volatile extracts from green tea, oolong tea, and black tea // J. Agric. Food Chem. 2003. Vol. 51, N25. Pp. 7396-7401.

14. Samusenko A.L. Comparative evaluation of antioxidant properties of spice-aromatic plant essential oils // Oxidation Communications. 2008. Vol. 31, N2. Pp. 275-284.

15. Мишарина Т.А. Автоокисление цитраля в присутствии одорантов // Химия растительного сырья. 2010 . №1. C. 93-98. 
Samusenko A.L. INVESTIGATION OF DEPENDENCE OF ANTIOXIDANT ACTIVITY OF ESSENTIAL OILS FROM CLOVE BUDS, LEMONGRASS, CARDAMOM AND BERRIES OF JUNIPER ON OIL CONCENTRATION BY CAPILLARY GAS-LIQUID CHROMATOGRAPHY

N.M. Emanuel Institute of Biochemical Physics RAS, Kosigina st., 4, Moscow, 119991 (Russia),

e-mail: Samusenko.alexey@rambler.ru

In recent time the biological activity of essential oils from spicy-aromatic herbs, including the antioxidant one, have been evaluated in numerous studies. Earlier we have demonstrated high antioxidant activity of the oils contained monoterpenes, such as $\gamma$-terpinene and $\alpha$-terpinolene, sesquiterpenes (zingeberene and $\beta$-caryofillene) and citral. However the concentration value of oils in the "aldehyde - essential oil" system was excessively high and the investigation of various concentrations was not carried out by us. The goal of this work was studying of the influence of oil concentration on antioxidant activity value for selected essential oils and correlation of the obtained data with a change of main antioxidants in the composition of the essential oils under study. The antioxidant properties of the essential oils from clove buds (Caryophyllus aromaticus L.), lemongrass (Cymbopogon citratus), cardamom (Elettaria cardamomum) and berries of juniper (Juniperus pinchoti) on oil concentration has been studied by capillary gas-liquid chromatography using an aldehyde/carboxylic acid assay. Trans-2-hexenal was selected to serve as the test substance. The dependence of oil antioxidant activity on its concentration was found to be closely connected with a rate of content change of main antioxidants in the composition of the essential oils under study at prolonged exposure to light. It was noted that the presence of strong antioxidants in oil composition even in relatively low quantities can significantly affect the value of their AOA and its dependence on the concentration of oil in the solution. It was observed the strong dependence «antioxidant activity - oil concentration» for clove and lemongrass oils. Low concentrations of all investigated oils, except for oil from clove buds, didn't have an inhibiting action on the oxidation of test-aldehyde.

Keywords: spicy-aromatic herbs, essential oils, antioxidant activity, capillary gas chromatography.

\section{References}

1. Burt S. Int. J. Food Microbiol., 2004, vol. 94, no. 3, pp. 223-253.

2. Hsu F.-L., Li W.-H., Yu C.-W., Hsieh Y.-C., Yang Y.-F., Liu J.-T., Shih J., Chu Y.-J., Yen P.-L., Chang S.-T., Liao V. H.-C. J. Agric. Food Chem., 2012, vol. 60, no. 12, pp. 3092-3097.

3. El-Ghorab H., Nauman M., Anjum F.M., Hussain S. and Nadeem M. J. Agric. Food Chem., 2010, vol. 58, no. 14, pp. 8231-8237.

4. Kulawik P., Özogul F., Glew R., Özogul Y. J. Agric. Food Chem., 2013, vol. 61, no. 3, pp. 475-491.

5. Chizzola R., Michitsch H., Franz C. J. Agric. Food Chem., 2008, vol. 56, no. 16, pp. 6897-6904.

6. Ruberto G., Baratta M. Food Chem., 2000, vol. 69, no. 2, pp. 167-174.

7. Cabrera A.C., Prieto J.M. Food Chem., 2010, vol. 118, no. 1, pp. 141-146.

8. Samusenko A.L. Oxidation Communications, 2008, vol. 31, no. 2, pp. 275-284.

9. Samusenko A.L. Oxidation Communications, 2008, vol. 31, no. 3, pp. 519-526.

10. Jennings W., Shibamoto T. Qualitative Analysis of Flavor and Fragrance Volatiles by Glass Capillary Gas Chromatography. New York; London ; Sydney ; Toronto ; San Francisco, 1980. 472 p.

11. Lee K.G., Shibamoto T. J. Agric. Food Chem., 2002, vol. 50, no. 17, pp. 4947-4952.

12. Lee K.G., Shibamoto T. Food and Chem. Toxicol., 2001, vol. 39, no. 12, pp. 1199-1204.

13. Yanagimoto K., Ochi H., Lee K.G., Shibamoto T. J. Agric. Food Chem., 2003, vol. 51, no. 25, pp. 7396-7401.

14. Samusenko A.L. Oxidation Communications, 2008, vol. 31, no. 2, pp. 275-284.

15. Misharina T.A. Khimiia rastitel'nogo syr'ia, 2010, no. 1, pp. 93-98. (in Russ.). 